\title{
Brush border enzyme activity and expression of apoptotic marker genes in lycopene fed rats with 5-Fu induced gastrointestinal mucositis
}

\author{
Raja A.H. Kuchay ${ }^{\mathrm{a}}$, Alka Bhatia ${ }^{\mathrm{a}}$, Akhtar Mahmood ${ }^{\mathrm{b}}$, Mumtaz Anwar ${ }^{\mathrm{a}}$ and Safrun Mahmood ${ }^{\mathrm{a}, *}$ \\ ${ }^{a}$ Department of Experimental Medicine and Biotechnology, Postgraduate Institute of Medical Education and \\ Research, Chandigarh, India \\ ${ }^{\mathrm{b}}$ Department of Biochemistry, Panjab University, Chandigarh, India
}

\begin{abstract}
.
Background: Gastrointestinal mucositis is a common side effect of cancer chemotherapy. It is characterized by mucosal damage and barrier function alterations.

Objective: We investigated the effect of single intraperitoneal dose (IP) of 5-Flurouracil (5-Fu) on the activity of brush border membrane enzymes like alkaline phosphatase (ALP), sucrase, lactase, leucine aminopeptidase (LAP) and $\gamma$-glutamyl transpeptidase $(\gamma$-GTP) in the small intestine of Wistar rats. Damage to various intestinal histopathological parameters was also examined after 5-Fu administration. Expression of various apoptotic and inflammatory marker genes in response to 5-Fu treatment was also studied. We also analysed the potential effect of lycopene supplementation in ameliorating the damage caused by 5 -Fu administration.

Methods: Adult male Wistar rats were randomised into four groups of ten animals each. Animals in the first group served as control, second group (5-Fu alone) was given a single IP dose of 5-Fu, third group (5-Fu + Lycopene) were orally administered lycopene, fourth group (Lycopene alone) were injected with PBS and orally given lycopene. Intestinal brush border enzyme activity was measured, followed by histopathological analyses and western blotting for protein expression studies of various apoptotic marker genes. Effect of lycopene supplementation on expression of Cox-2 was also analysed.

Results: IP dose of 5-Fu resulted in a significant decrease in the activity of brush border enzymes $(P<0.05)$. Villus shortening and fusion, epithelial atrophy, crypt loss and inflammatory infiltrate in the lamina propria were also observed after 5-Fu treatment compared with control group $(P<0.05)$. There was a significant increase in protein expression of pro-apoptotic genes (Bax, Bak) after administration of 5-Fu $(P<0.05)$. There was an increased expression of $\mathrm{Cox}-2$ in rats treated with 5-Fu alone compared to control group rats $(P<0.05)$. Supplementation of lycopene two days before and after a single IP dose of 5-Fu significantly improved the activity of ALP, LAP and $\gamma$-GTP as compared to 5-Fu group $(P<0.05)$. However, no such improvement was observed in case of lactase and sucrase. Inflammatory infiltrate in the lamina propria was also significantly decreased in 5-Fu + lycopene treated rats compared to 5-Fu alone treated group. There was a significant decrease in the expression of Cox- 2 after lycopene supplementation $(P<0.05)$.

Conclusion: Lycopene supplementation improved some gastrointestinal parameters after a single IP dose of 5-Fu. This may be due to the anti-inflammatory effect of lycopene. Further studies are needed to explore the potential of lycopene as a nutritional supplement for 5-Fu induced gastrointestinal mucositis.
\end{abstract}

Keywords: Lycopene, 5-Fu, gastrointestinal mucositis, antioxidant

\footnotetext{
${ }^{*}$ Corresponding author: Dr. Safrun Mahmood, Geneticist, Department of Experimental Medicine and Biotechnology, Postgraduate Institute of Medical Education and Research, Chandigarh
}

160012, India. Tel.: +91 172 2755237; Fax: +91 172 2744401; E-mail: mahmoodpgi@gmail.com. 


\section{Introduction}

Administration of chemotherapy often leads to gastrointestinal mucositis [1]. Mucositis manifests as nausea, abdominal pain and diarrhoea in recipients of chemotherapy [2]. Induction of apoptosis in intestinal epithelial cells of experimental animals has been observed after administration of various cytotoxic agents [3]. High rate of cell proliferation and differential expression of apoptosis regulating proteins have been attributed to increased susceptibility of small intestinal cells to chemotherapy induced apoptosis [3]. It has also been suggested that apoptosis of stem cells in the lower part of the epithelial crypts further compounds the intestinal injury by damaging the cell regeneration [3, 4]. Intestinal brush border membrane (BBM) lines the single layer of epithelial cells in the gut lumen and plays a major role in digestion and absorption of nutrients [5]. Chemotherapy induced damage of BBM may be revealed by altered activities of various brush border bound marker enzymes as has been reported for various other toxic compounds [6-8].

5-Flurouracil (5-Fu) is a frequently used chemotherapy agent in clinical oncology practice [9]. Gastrointestinal mucositis is a major complication occurring in approximately $80 \%$ of patients receiving 5-Fu treatment [10]. Lycopene, a carotenoid antioxidant with high number of conjugated double bonds is found in certain foods, most notably tomatoes [11]. Due to its singlet oxygen quenching ability, lycopene is suggested to have potent antioxidant activity and may exert a protective effect in various diseases [12]. Results indicate a protective role of lycopene in cisplatin-induced nephrotoxicity and oxidative stress in rat [13]. The addition of lycopene as adjuvant to radiotherapy and chemotherapy in treatment of high grade gliomas had a positive outcome in terms of response rates and time to progression [14]. Lack of literature on lycopene supplementation in chemotherapy has warranted further studies to establish the ameliorating/non-ameliorating effect of this antioxidant on chemotherapy induced damage to the gastrointestinal system.

The aim of present study was to examine the potential of lycopene supplementation in ameliorating the damage caused by $5-\mathrm{Fu}$ administration on various intestinal parameters like brush border membrane marker enzymes, severity of damage to various intestinal histopathological parameters and expression of various apoptotic marker genes. Brush border marker enzymes included alkaline phosphatase (ALP), leucine aminopeptidase (LAP), $\gamma$-glutamyl transpeptidase $(\gamma$ GTP), sucrase and lactase. Apoptotic marker genes included in this study were pro-apoptotic (Bax, Bak) and anti-apoptotic (Bcl-2, Bcl-xL). Effect of lycopene supplementation on expression of Cox-2 was also analysed.

\section{Materials and methods}

\subsection{Animals and experimental design}

Adult male Wistar rats weighing 150-200g were obtained from central animal house of the Institute. Rats were housed in clean wire mesh cages with controlled temperature $\left(23 \pm 1^{\circ} \mathrm{C}\right)$ and humidity (45-55\%) and with a $12 \mathrm{~h}$ dark- $12 \mathrm{~h}$ light cycle throughout the study. Animals were stabilized for 7 days prior to the experiments and then randomised into four groups of ten animals each. Animals in the first group served as control and were injected intraperitoneally (IP) with phosphate-buffered saline (PBS) (137 mM NaCl, $1.4 \mathrm{mM} \mathrm{KH} \mathrm{PO}_{4}, 4.3 \mathrm{mM} \mathrm{Na} 2 \mathrm{HPO}_{4}$, $2.7 \mathrm{mM} \mathrm{KCl}, \mathrm{pH}$ 7.2). The second group (5-Fu alone) was given a single IP dose of $5-\mathrm{Fu}(100 \mathrm{mg} / \mathrm{kg}$ body weight). Animals in the third group (5-Fu + Lycopene) were orally administered lycopene $(5 \mathrm{mg} / \mathrm{kg}$ body weight) for two consecutive days before and after the administration of single IP dose of 5-Fu. Animals in the fourth group (Lycopene alone) were injected with PBS and orally given lycopene. The animals had free access to water. Two days after receiving IP 5-Fu dose, animals from all the four groups were sacrificed under light ether anaesthesia. Starting from the ligament of Treitz, two-thirds of the small intestine was removed, flushed with ice-cold saline and processed for biochemical analyses. Part of tissues was fixed in $10 \%$ formalin, blocks were made by embedding in paraffin wax. Haematoxylin \& eosin (HE) staining of the tissue sections was carried out for microscopic examination.

\subsection{Ethical committee declaration}

The experimental protocol was approved by the ethical committee of the institute (PGIMER, Chandigarh) on the use of laboratory animals. Experiments on animals were performed in accordance with the guidelines for the use of laboratory animals. 


\subsection{Isolation of intestinal brush border membrane (BBM)}

Intestine starting from ligament of Treitz to caecum was removed and washed thoroughly with ice-cold isotonic sodium chloride solution. Intestinal weight and length were measured. The brush border membranes were isolated and purified by the method of Kesseler et al. [15]. Briefly, intestinal tissue was homogenized in ice-cold buffer containing $50 \mathrm{mM}$ mannitol and $2 \mathrm{mM}$ Tris ( $\mathrm{pH}$ 7.2). Solid calcium chloride was added to the homogenate (final concentration, $10 \mathrm{mM}$ ) and allowed to stand on ice for $15 \mathrm{~min}$ followed by centrifugation at $3000 \mathrm{~g}$ for $15 \mathrm{~min}$ at $4{ }^{\circ} \mathrm{C}$. The supernatant was subjected to centrifugation at $42,000 \mathrm{~g}$ for $30 \mathrm{~min}$ at $4^{\circ} \mathrm{C}$. The pellet obtained was suspended in $50 \mathrm{mM}$ sodium maleate, $\mathrm{pH}$ 6.8. The membrane preparation exhibited 12- to 13-fold enrichment of brush border marker enzymes over the crude homeogenate.

\subsection{Assay of brush border enzymes}

The activities of sucrase and lactase were assayed using respective disaccharide as substrate and glucose oxidase-peroxidase system as described by Dahlqvist [16]. ALP activity was determined using p-nitrophenyl phosphate as substrate [17]. LAP activity was determined by the method of Goldbarg and Rutenberg [18]. The activity of $\gamma$-GTP was determined by method of Naftalin et al. [19]. Protein was estimated using bovine serum albumin as the substrate by the method of Lowry et al. [20]. Enzyme activities were expressed as units/gram (U/g) protein. One unit of enzyme activity equals the amount of the enzyme that transforms $1 \mu \mathrm{mol}$ of substrate to product per min, under the standard assay conditions.

\subsection{Histopathology}

The tissue samples of the jejunum were fixed by $10 \%$ neutral formalin, embedded in paraffin and cut with a microtome set at a thickness of 5-6 $\mu \mathrm{m}$. The tissue sections were stained with $\mathrm{HE}$ and examined with a light microscope. HE-stained tissue sections were examined for villus structure, histopathological alterations in crypt cells and mononuclear cell infiltration in lamina propria. The appearance of all groups was scored by a single observer (blinded to treatment) as follows: no lesion $=0$; mild damage $=1$; moderate damage $=2$, and severe damage $=3$ [21] .

\subsection{Western blotting}

2-5 mg piece of intestinal tissue was homogenized in a tube containing $\sim 300 \mu$ l RIPA lysis buffer (150 mM sodium chloride, $1.0 \%$ Triton X-100, 0.5\% sodium deoxycholate, $0.1 \%$ SDS) using an electric homogenizer. Protease inhibitor cocktail (Roche Diagnostics, Indianapolis) was immediately added to the tube. Homogenate was centrifuged for $10 \mathrm{~min}$ at $5000 \mathrm{rpm}$ at $4^{\circ} \mathrm{C}$ in a microcentrifuge. Supernatant was removed and placed in a fresh tube, pellet was discarded. Protein was estimated using bovine serum albumin as the substrate by the method of Lowry et al. [20]. Proteins were resolved on SDS-PAGE following the method of Lammeli [22]. Western blot analysis was performed following the method described by Mahmood et al. [23]. For protein expression studies, $100 \mu \mathrm{g}$ protein was resolved on $12 \%$ SDS-PAGE and transferred to PVDF membrane (Millipore, Billerica, MA) for $20 \mathrm{~min}$ at $15 \mathrm{~V}$. The membrane was incubated overnight in blocking buffer (5\% dry milk in $20 \mathrm{mM}$ phosphate buffer, $\mathrm{pH} 7.4$ ) at $4^{\circ} \mathrm{C}$. The primary antibody against Bax, Bcl-2, Bcl-xL (Travigen Inc, Gaithersburg, MD, USA) and Cox-2, Bak (Santa Cruz Biotechnology, Inc) was used in 1:500 dilution. The secondary antibody (Banglore Genei, India) was HRP linked and used in 1:1000 dilution. Resulting blots were developed using 3,3-diaminobenzidine tetrahydrochloride as substrate in the presence of $30 \% \mathrm{H}_{2} \mathrm{O}_{2}$.

\section{Statistics}

The values are presented as the means \pm SD. Group means were compared using Student's $t$-test. The acceptable level of significance was $P<0.05$ for each analysis.

\section{Results}

\subsection{Brush border enzymes activities}

There was a significant decrease $(P<0.05)$ in the activities of all brush border membrane enzymes after the administration of single IP dose of 5-Fu. The fold 


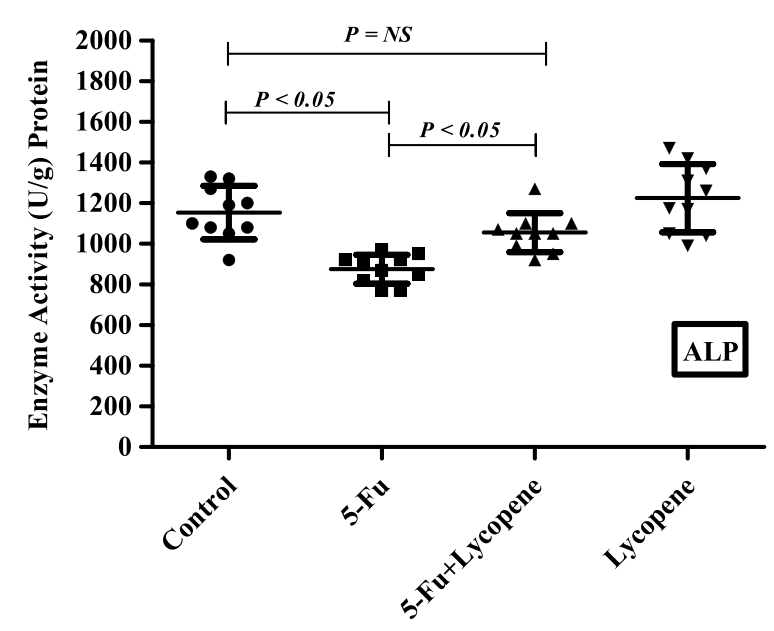

Fig. 1. Scatter plot for variation of ALP activity in the intestinal brush border membrane of Control, 5-Fu, 5 Fu+ Lycopene and Lycopene (only) treated rats.

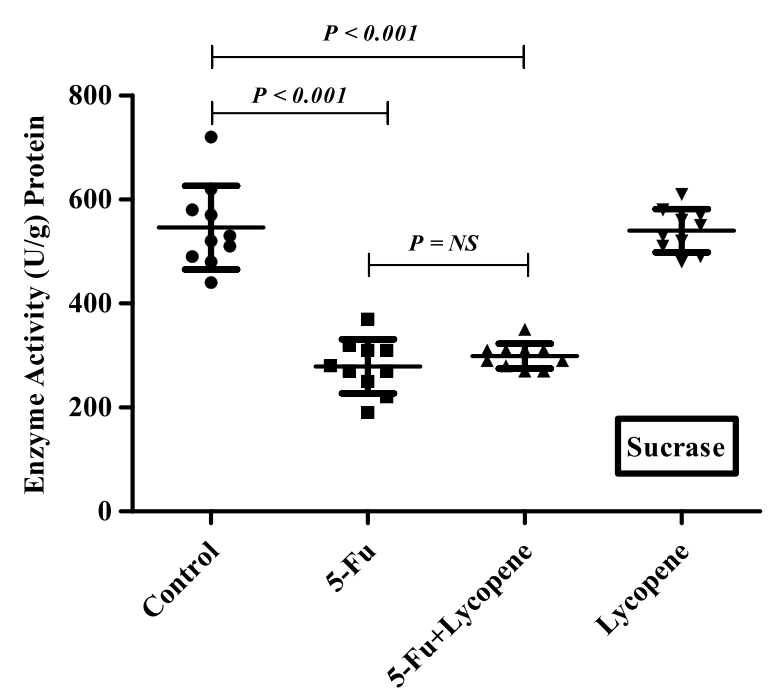

Fig. 2. Scatter plot for variation of Sucrase activity in the intestinal brush border membrane of Control, 5-Fu, 5 Fu+ Lycopene and Lycopene (only) treated rats.

decrease in enzyme activities for 5-Fu group compared to control group was $24.1 \%, 49 \%, 59.3 \%, 22.3 .9 \%$ and $25.9 \%$ for ALP, sucrase, lactase LAP and $\gamma$-GTP respectively. In case of 5-Fu + Lycopene group, the fold decrease compared to control group was $8.5 \%$, $45.2 \%, 53.7 \%, 8 \%$ and $7.7 \%$ for ALP, sucrase, lactase LAP and $\gamma$-GTP respectively. Thus, supplementation of lycopene two days before and after a single IP dose of 5-Fu significantly improved the activities of ALP, LAP and $\gamma$-GTP (Figs. 1-5). However, activities of

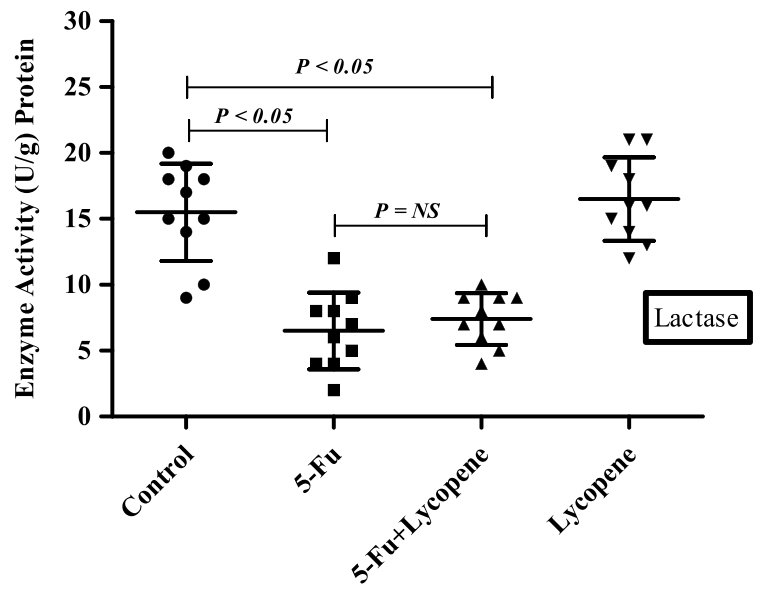

Fig. 3. Scatter plot for variation of Lactase activity in the intestinal brush border membrane of Control, 5-Fu, $5 \mathrm{Fu}+$ Lycopene and Lycopene (only) treated rats.

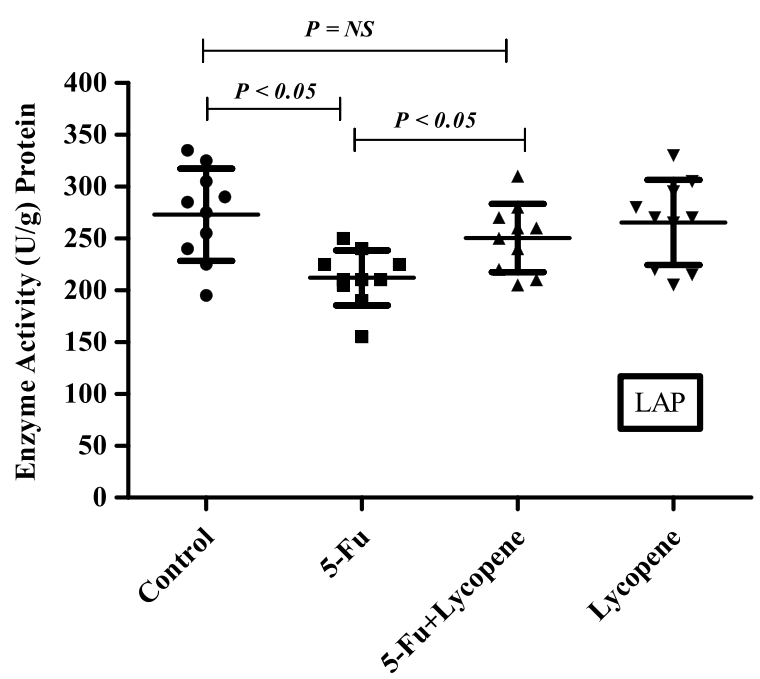

Fig. 4. Scatter plot for variation of LAP activity in the intestinal brush border membrane of Control, 5-Fu, $5 \mathrm{Fu}+$ Lycopene and Lycopene (only) treated rats.

sucrase and lactase did not improve significantly. For ALP, the mean activity in control, 5-Fu and 5-Fu + Lycopene treated groups was $1154 \mathrm{U} / \mathrm{g}, 875 \mathrm{U} / \mathrm{g}$ and $1055 \mathrm{U} / \mathrm{g}$ protein respectively. For sucrase, the mean enzyme activity in these three groups was $546 \mathrm{U} / \mathrm{g}, 279$ $\mathrm{U} / \mathrm{g}$ and $299 \mathrm{U} / \mathrm{g}$ protein respectively. For lactase, the mean enzyme activity in three groups was $16 \mathrm{U} / \mathrm{g}, 6.5$ $\mathrm{U} / \mathrm{g}$ and $7.4 \mathrm{U} / \mathrm{g}$ protein respectively. For LAP and $\gamma$ GTP, mean enzyme activity for three groups was 273 $\mathrm{U} / \mathrm{g}, 212 \mathrm{U} / \mathrm{g}, 251 \mathrm{U} / \mathrm{g}$ and $181.5 \mathrm{U} / \mathrm{g}, 134.5 \mathrm{U} / \mathrm{g}, 167$ 


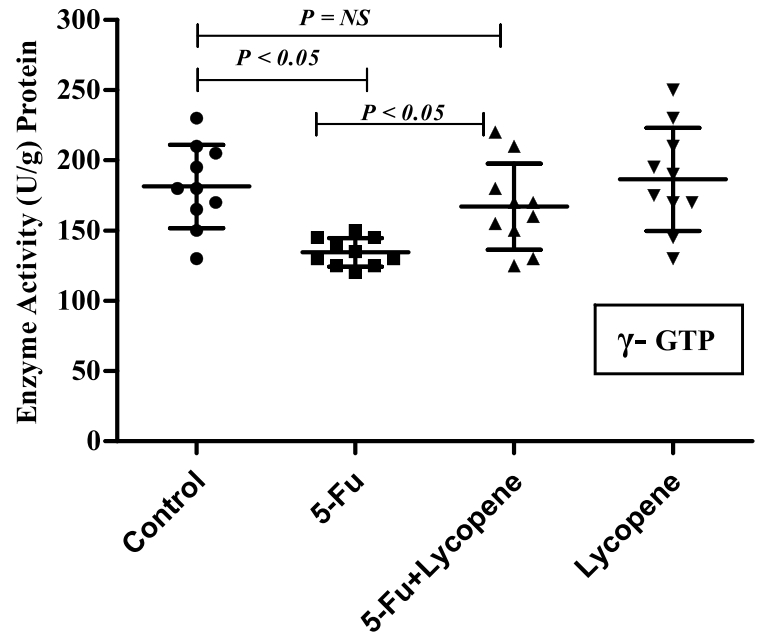

Fig. 5. Scatter plot for variation of $\gamma$-GTP activity in the intestinal brush border membrane of Control, 5-Fu, $5 \mathrm{Fu}+$ Lycopene and Lycopene (only) treated rats.

$\mathrm{U} / \mathrm{g}$ protein respectively. Administration of lycopene alone did not have a significant effect on enzyme activities which were similar to the controls.

\subsection{Histopathology}

Compared to the control group, the tissue sections of the rats treated with 5 -Fu alone had villus shortening and fusion with variable degrees of epithelial atrophy. Decrease in the number of crypt cells, crypt loss and crypt inflammatory infiltrate in the lamina propria was also observed. The histopathological findings in 5-Fu + Lycopene group were almost similar to those in rats treated with 5-Fu alone. However, a significant decrease in inflammatory infiltrate was observed in rats treated with 5-Fu + Lycopene compared to 5-Fu alone group (Fig. 6).

\subsection{Western blotting}

Changes in protein expression of pro-apoptotic (Bax, Bak) and anti-apoptotic (Bcl-2, Bcl-xL) genes was investigated after 5-Fu and 5-Fu + Lycopene treatment. There was a significant increase in the expression of Bax and Bak after a single IP dose of 5-Fu compared to control group $(P<0.05)$. The results were similar for 5-Fu + Lycopene treated group. For anti-apoptotic genes (Bcl-2, Bcl-xL), changes in protein expression compared to control group were not significant (Fig. 7). There was an increased expression of Cox-2 in rats

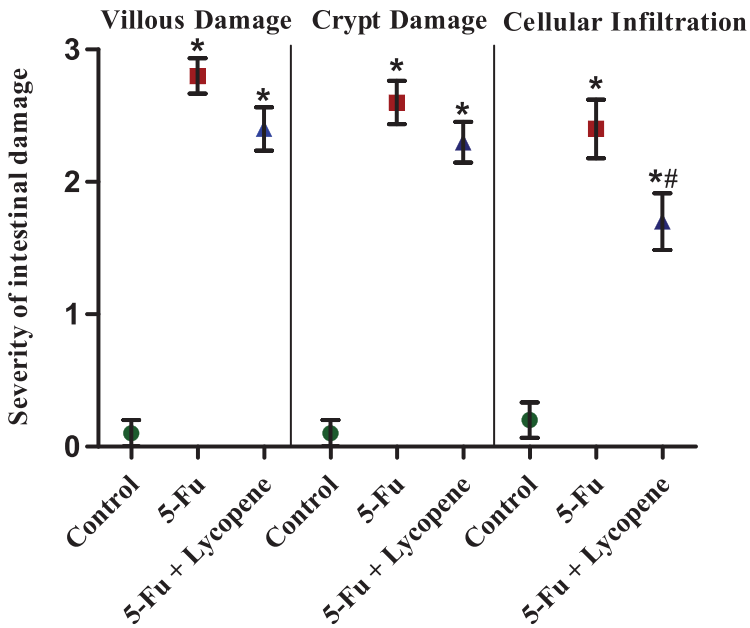

Fig. 6. The severity of intestinal tissue damage for various parameters in Control, 5-Fu and $5 \mathrm{Fu}+$ Lycopene treated rats. Values represented as Mean $\pm \mathrm{SD}$. *Significantly different from control group. "Significantly different from 5-Fu group.

treated with $5-\mathrm{Fu}$ alone compared to control group rats $(P<0.05)$. The difference in protein expression of pro and anti-apoptotic genes between $5-\mathrm{Fu}$ and 5-Fu + Lycopene groups was not significant (Fig. 7). However, a significant decrease in the expression of Cox-2 after lycopene supplementation $(P<0.05)$.

\section{Discussion}

The present study was undertaken to investigate the effect of lycopene supplementation two days before and after a single IP dose of 5-Fu on the brush border membrane enzyme activity, histopathological parameters and expression of apoptotic marker genes in the intestine of Wister rats. 5-FU is a commonly used chemotherapy drug for the treatment of malignant tumors. It kills tumor cells through interfering DNA synthesis and affecting protein synthesis [9]. However, most of the cytotoxic agents also cause indiscriminate damage to certain healthy tissue. Mucositis has been observed in $40 \%$ of patients after standard doses of chemotherapy, and in $100 \%$ of patients undergoing high dose of chemotherapy [1]. The current experimental observations in rat intestinal mucosa after a single IP dose of 5-Fu demonstrate a significant reduction in the activities of brush border membrane enzymes including ALP, sucrase, lactase, LAP and $\gamma$-GTP. Intestinal ALP has already been shown to be a good marker 
A

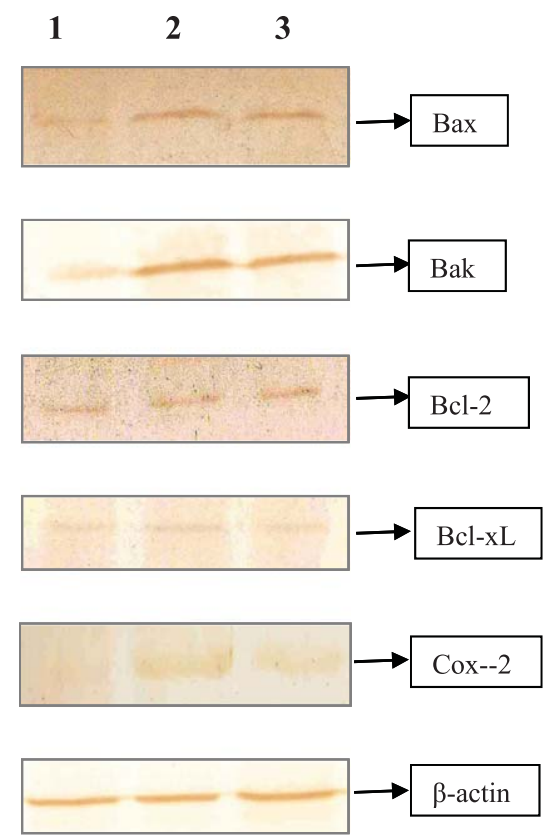

B

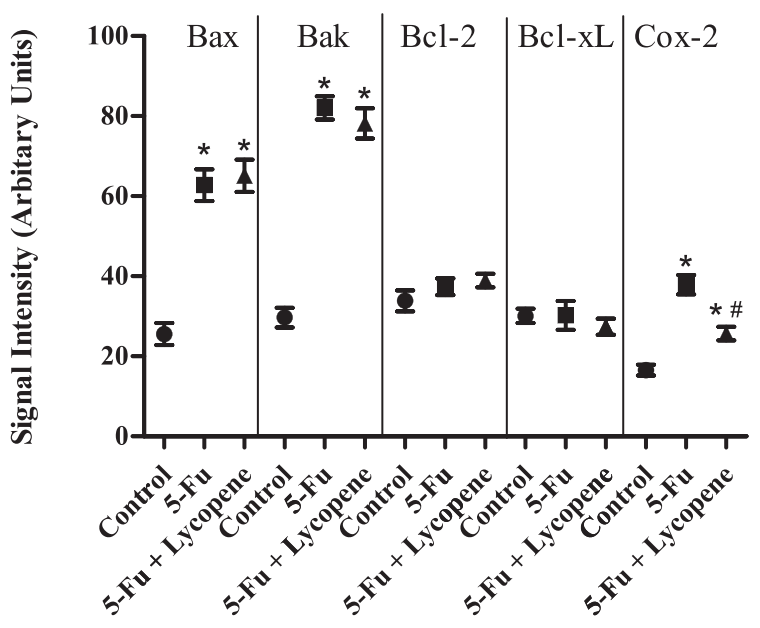

Fig. 7. (A) Western blot for protein expression of various proapoptotic, anti-apoptotic and anti-inflammatory marker genes in control (Lane 1), 5-Fu (Lane 2) and 5-Fu + Lycopene (Lane 3) treated rats. $100 \mu \mathrm{g}$ protein was resolved on $12 \%$ SDS-PAGE and transferred to PVDF membrane for western blotting. (B) Densitometric scan of the corresponding blots as represented in arbitrary units. Values represented as Mean $\pm \mathrm{SD}$. *Significantly different from control group; "Significantly different from 5-Fu alone group. of the dose-dependent enterotoxicity induced by $5-\mathrm{Fu}$ [24]. The activities of sucrase and lactase were most severely affected followed by that of ALP after an IP dose of 5-Fu. Lactase being located on the most distal side of the villus, is usually one of the first and most severely affected. The significant decrease in the activity of intestinal brush border membrane enzymes may be attributed to the downregulation of the expression through some transcriptional factor or the inhibition of overall DNA synthesis due to cytotoxic drug. It has been suggested that initiating event in chemotherapy involves the generation of oxidative stress and reactive oxygen species followed by activation of NF- $\kappa b$ resulting in tissue injury and apoptosis [25]. Besides the decrease in brush border membrane enzymes, exposure to 5-Fu resulted in shortened villi and crypts, due to reduced cellularity [26]. In this study, the general characteristics (villus atrophy, crypt loss) due to 5-Fu induced small intestinal mucositis were similar as described in previous studies for various cytotoxic agents [21, 27].

Lycopene is a naturally present carotenoid in tomatoes. Antioxidant potential of lycopene has been demonstrated in many cellular and molecular studies wherein it has been suggested to prevent carcinogenesis and atherogenesis by protecting critical biomolecules such as DNA, proteins, lipids and lowdensity lipoproteins (LDLs) [28]. Saada et al. proposed that pre-treatment with lycopene for 7 successive days before irradiation protects cellular membrane from radiation-induced lipid peroxidation, maintaining the arhitecture of small intestine and preventing the release of monoamines [29]. In the present study, supplementation of lycopene significantly improved the activities of ALP, LAP and $\gamma$-GTP. Also, there was a significant decrease in inflammatory infiltrate in 5-Fu + Lycopene treated group compared to 5$\mathrm{Fu}$ alone. This may be due to the anti-inflammatory effect of lycopene as has been reported in various other findings $[30,31]$. Lycopene has been reported to reduce inflammation by inhibiting the release of TNF- $\alpha$ and stimulating IL-10 production [31]. Possible mechanisms for its anti-inflammatory response may include the inhibition of synthesis and release of proinflammatory cytokines, changes in the expression of cyclooxygenase, modifications of eicosanoid synthesis, and modulation of signal transduction pathways, including that of the inducible nitric oxide synthase via its inhibitory effects on NF-кB [32]. There was a significant decrease on $\mathrm{Cox}-2$ expression in $5-\mathrm{Fu}$ 
+ Lycopene treated group suggesting a potential antiinflammatory role of lycopene in chemotherap induced mucositis. The role of Cox-2 and nitric oxide-synthase during chemotherapy or radiation induced mucositis has been demonstrated [33, 34].

We also analysed the protein expression of various pro-apoptotic (Bax, Bak) and anti-apoptotic (Bcl-2, $\mathrm{Bcl}-\mathrm{xL}$ ) genes after administration of 5-Fu and 5-Fu + Lycopene. Protein expression of Bax and Bak was significantly increased in 5-Fu treated group compared to control group. These results are consistent with the findings of Bowen et al. [35] regarding transient increase in pro-apoptotic gene expression of Bax and Bak after cytotoxic drug treatment [35]. However, the expression of Bcl-2 and Bcl-xL was not significantly different in 5-Fu group as compared to control group. It has been suggested that high $\mathrm{Bax}$ and low $\mathrm{Bcl}-2$ protein expression in intestinal crypts of murine and human small intestine is correlated to high levels of apoptosis, which is a hallmark of chemotherapy induces gastrointestinal mucositis [36, 37]. Furthermore, treatment with lycopene did not cause any significant change in the expression of pro or anti-apoptotic genes after a single IP dose of 5-Fu.

Various anti-oxidants have been suggested to ameliorate the effect of chemotherapy and radiotherapy induced gastrointestinal mucositis [21, 29]. Many studies have proposed clinical benefit of anti-oxidants during various cancer therapies [38-40]. However, Lawenda et al. [41] concluded that the use of supplemental antioxidants during chemotherapy and radiation therapy should be discouraged because of the possibility of tumor protection and reduced survival [41]. Our findings indicate that supplementation of lycopene two days before and after a single IP dose of 5-Fu significantly improved the activity of brush border enzymes like ALP, LAP and $\gamma$-GTP. Lycopene supplementation also decreased inflammatory infiltrate in the lamina propria. Significant decrease in Cox-2 expression in 5-Fu+lycopene treated group was also reported. This may suggest a potential anti-inflammatory effect of lycopene in 5-fu induced gastrointestinal mucositis. However, lycopene supplementation did not significantly improve the activities of lactase and sucrase. Expression of apoptotic genes was also not significantly affected. The results from present study indicate that the role of lycopene in ameliorating the effect of chemotherapy induced mucositis may warrant further study with dose, duration and signalling pathway activated by lycopene exposure being the critical aspects.

\section{Acknowledgments}

We thank Sunil Kumar Sharma (Arjun) for animal handling. We acknowledge the help of Ms. Rekha Virli during dosing of animals. Laboratory of Dr. Safrun Mahmood was supported by Department of Biotechnology (DBT), New Delhi, India.

\section{Conflict of interests}

None of the authors reported any personal or financial conflict of interests.

\section{References}

[1] Keefe DM, Cummins AG, Dale BM, Kotasek D, Robb TA, Sage RE. Effect of high-dose chemotherapy on intestinal permeability in humans. Clin Sci. 1997;92:385-9.

[2] Keefe DM. Gastrointestinal mucositis: A new biological model. Support Care Cancer. 2004;12(1):6-9.

[3] Keefe DM, Brealey J, Goland GJ, Cummins AG. Chemotherapy for cancer causes apoptosis that precedes hypoplasia in crypts of the small intestine in humans. Gut. 2000;47(5):632-7.

[4] Potten CS, Wilson JW, Booth C. Regulation and significance of apoptosis in the stem cells of the gastrointestinal epithelium. Stem Cells. 1997; 15:82-93.

[5] Madar JL, Trier JS. Physiology of the Gastrointestinal Tract. In: Johnson LR (ed) Raven Press, New York; 1987. pp. 1209-1249.

[6] Kapur P, Kaur K, Mahmood A. Expression of brush border enzymes in response to lead exposure in rat intestine. J Appl Toxicol. 2005;25(5):361-4.

[7] Singla A, Kaur J, Mahmood A. Alterations in the expression of intestinal enzymes in rats exposed to nickel. J Appl Toxicol. 2006;26(5):397-401.

[8] Gupta S, Mahmood S, Khan RH, Mahmood A. Inhibition of brush border sucrase by polyphenols in mouse intestine. Biosci Rep. 2010;30:111-7.

[9] Longley DB, Harkin DP, Johnston PG. 5-fluorouracil: Mechanisms of action and clinical strategies. Nat Rev Cancer. 2003;3:330-8.

[10] Sonis ST, Elting LS, Keefe D, Peterson DE, Schubert M, Hauer-Jensen M, Bekele BN, Raber-Durlacher J, Donnelly JP, Rubenstein EB. Perspectives on cancer therapy-induced mucosal injury: Pathogenesis, measurement, epidemiology, and consequences for patients. Cancer. 2004;100:1995-2025.

[11] Rao AV, Agarwal S. Role of antioxidant lycopene in cancer and heart disease. J Am Coll Nutr. 2000;19:563-9.

[12] Tsen KT, Tsen SW, Kiang JG. Lycopene is more potent than beta carotene in the neutralization of singlet oxygen: Role of energy transfer probed by ultrafast Raman spectroscopy. J Biomed Opt. 2006;11(6):064025.

[13] Atessahin A, Yilmaz S, Karahan I, Ceribasi AO, Karaoglu A. Effects of lycopene against cisplatin-induced nephrotoxicity and oxidative stress in rats. Toxicology. 2005;212(2-3):116-23.

[14] Puri T, Julka TK, Goyal S, Nair O, Sharma DN, Rath GK. Role of natural lycopene and phytonutrients along with radiotherapy 
and chemotherapy in high grade gliomas. Journal of Clinical Oncology. 2005;23(16):1561-7.

[15] Kessler M, Acuto O, Storelli C, Murer H, Müller M, Semenza G. A modified procedure for rapid preparation of efficiently transporting vesicles from small intestinal brush border membrane. Biochem Biophys Acta. 1978;506:136-54.

[16] Dahlqvist A. Assay of intestinal disaccharidases. Scand J Clin Lab Invest. 1984;44:169-72.

[17] Bergmeyer MVC. Methods of Enzymatic Analysis. New York: Academic Press. 1963;783-5.

[18] Goldbarg JA, Rutenburg AM. The colorimetric determination of leucine aminopeptidase in urine and serum of normal subjects and patients with cancer and other diseases. Cancer. 1958;11:283-91.

[19] Naftalin L, Sexton M, Whitaker JF, Trucey DA. Routine procedure for estimating serum gamma-glutamyl transpeptidase activity. Clin Chem Acta. 1969;26:293-6.

[20] Lowry OH, Rosenbrough NJ, Farr AL, Randall RJ. Protein measurement with the folin phenol reagent. J Biol Chem. 1951;193:265-75

[21] Yüncü M, Eralp A, Koruk M, Sari I, Bağci C, Inalöz S. Effect of vitamin $A$ against methotrexate-induced damage to the small intestine in rats. Med Princ Pract. 2004;13(6):346-52.

[22] Lammeli UK. Cleavage of structural proteins during the assembly of the head of bacteriophage T4. Nature. 1970;227:680-5.

[23] Mahmood A, Mahmood S, Desehryver-KecsKimeti K, Alpers DH. Characterization of proteins in rat and human intestinal surfactant particles. Arch Biochem Biophys. 1993;300:280-6.

[24] Bajin-Katić K, Stankov K, DJolai M, Kovačević Z. molecular marker of enterotoxicity induced by single dose of 5-fluorouracil and protective role of orally administered glutamine. Archive of Oncology. 2006;14(3-4):101-5.

[25] Bowen JM, Gibson RJ, Cummins AG, Keefe DM. Intestinal mucositis: The role of the Bcl-2 family, p53 and caspases in chemotherapy-induced damage. Support Care Cancer. 2006;14(7):713-31.

[26] Logan RM, Stringer AM, Bowen JM, Yeoh AS, Gibson RJ, Sonis ST, Keefe DM. The role of pro-inflammatory cytokines in cancer treatment-induced alimentary tract mucositis: Pathobiology, animal models and cytotoxic drugs. Cancer Treat Rev. 2007;33(5):448-60

[27] Naruhashi K, Nadai M, Nakao M, Suzuki N, Nabeshima T, Hasegawa T. Changes in absorptive function of rat intestine injured by methotrexate. Clin Exp Pharmacol Physiol. 2000;27:980-6

[28] Basu A, Imrhan V. Tomatoes versus lycopene in oxidative stress and carcinogenesis: Conclusions from clinical trials. Eur J Clin Nutr. 2007;61(3):295-303.

[29] Saada HN, Rezk RG, Eltahawy NA. Lycopene protects the structure of the small intestine against gamma-radiation- induced oxidative stress. Phytother Res Suppl. 2010;2: S204-8.

[30] Jacob K, Periago MJ, Bohm V, Berruezo GR. Influence of lycopene and vitamin $\mathrm{C}$ from tomato juice on biomarkers of oxidative stress and inflammation. British Journal of Nutrition. 2008;99(1):137-46.

[31] Hazewindus M, Haenen G, Weseler AR, Bast A. The antiinflammatory effect of lycopene complements the antioxidant action of ascorbic acid and $\alpha$-tocopherol. Food Chemistry. 2012;132(2):954-8.

[32] Palozza P, Parrone N, Catalano A, Simone R. Tomato lycopene and inflammatory cascade: Basic interactions and clinical implications. Curr Med Chem. 2010;17(23):2547-63.

[33] Sonis ST, O'Donnell KE, Popat R, Bragdon C, Phelan S, Cocks D, Epstein JB. The relationship between mucosal cyclooxygenase-2 (COX-2) expression and experimental radiation-induced mucositis. Oral Oncol. 2004;40:170-6.

[34] Leitão RF, Ribeiro RA, Bellaguarda EA, Macedo FD, Silva LR, Oriá RB, Vale ML, Cunha FQ, Brito GA. Role of nitric oxide on pathogenesis of 5-fluorouracil induced experimental oralmucositis in hamster. Cancer Chemother Pharmacol. 2007;59:603-12.

[35] Bowen JM, Gibson RJ, Keefe DM, Cummins AG. Cytotoxic chemotherapy upregulates pro-apoptotic Bax and Bak in the small intestine of rats and humans. Pathology. 2005;37(1):5662.

[36] Potten CS, Li YQ, O'Connor PJ, Winton DJ. A possible explanation for the differential cancer incidence in the intestine, based on distribution of the cytotoxic effects of carcinogens in the murine large bowel. Carcinogenesis. 1992;13:2305-12.

[37] Krajewski S, Krajewska M, Shabaik A, Miyashita T, Wang HG, Reed JC. Immunohistochemical determination of in vivo distribution of Bax, a dominant inhibitor of Bcl-2. Am J Pathol. 1994;145:1323-36.

[38] Prasad KN. Multiple dietary antioxidants enhance the efficacy of standard and experimental cancer therapies and decrease their toxicity. Integr Cancer Ther. 2004;3(4):310-22.

[39] Block KI, Koch AC, Mead MN, Tothy PK, Newman RA, Gyllenhaal C. Impact of antioxidant supplementation on chemotherapeutic efficacy: A systematic review of the evidence from randomized controlled trials. Cancer Treat Rev. 2007;33(5):407-18.

[40] Simone CB 2nd, Simone NL, Simone V, Simone CB. Antioxidants and other nutrients do not interfere with chemotherapy or radiation therapy and can increase kill and increase survival, part 1. Altern Ther Health Med. 2007;13(1):22-8.

[41] Lawenda BD, Kelly KM, Ladas EJ, Sagar SM, Vickers A, Blumberg JB. Should supplemental antioxidant administration be avoided during chemotherapy and radiation therapy? J Natl Cancer Inst. 2008;100(11):773-83. 